\title{
Dendritic Cells in Barrett's Esophagus and Esophageal Adenocarcinoma
}

\author{
Yuri V. Bobryshev • Dinh Tran • \\ Murray C. Killingsworth • Michael Buckland • \\ Reginald V. N. Lord
}

Received: 19 June 2008 / Accepted: 8 July 2008 / Published online: 7 August 2008

(C) 2008 The Author(s)

\begin{abstract}
Background Like other premalignant conditions that develop in the presence of chronic inflammation, the development and progression of Barrett's esophagus is associated with the development of an immune response, but how this immune response is regulated is poorly understood. A comprehensive literature search failed to find any report of the presence of dendritic cells in Barrett's intestinal metaplasia and esophageal adenocarcinoma and this prompted our study.

Material and Methods We used immunohistochemical staining and electron microscopy to examine whether dendritic cells are present in Barrett's esophagus and esophageal adenocarcinoma. Immunohistochemical staining with CD83, a specific marker for dendritic cells, was performed on paraffin-embedded sections of Barrett's intestinal metaplasia (IM, $n=12$ ), dysplasia $(n=11)$ and adenocarcinoma $(n=14)$.

Results CD83+ cells were identified in the lamina propria surrounding intestinal type glands in Barrett's IM, dysplasia, and cancer tissues. Computerized quantitative analysis showed that the numbers of dendritic cells were significantly higher in cancer tissues. Double immunostaining with CD83, CD20, and CD3, and electron microscopy demonstrated that dendritic cells are present in Barrett's esophagus and form clusters with T cells and B cells directly within the lamina propria.

Conclusions These findings demonstrate that dendritic cells are present in Barrett's tissues, with a significant increase in density in adenocarcinoma compared to benign Barrett's esophagus. Dendritic cells may have a role in the pathogenesis and immunotherapy treatment of Barrett's esophagus and adenocarcinoma.
\end{abstract}

Electronic supplementary material The online version of this article (doi:10.1007/s11605-008-0613-9) contains supplementary material, which is available to authorized users.

The research was supported by the National Health and Medical Research Council, Cancer Institute NSW, and St. Vincent's Clinic Foundation, Sydney.

Y. V. Bobryshev

Department of Surgery and Centre for Immunology,

St Vincent's Hospital, University of New South Wales,

Sydney, Australia

Y. V. Bobryshev

Faculty of Medicine, University of New South Wales,

Kensington, NSW 2052, Australia

D. Tran $\cdot$ M. Buckland

Division of Anatomical Pathology, St. Vincent's Hospital,

Sydney, Australia
M. C. Killingsworth

Department of Anatomical Pathology, South Western Area Pathology Service, Liverpool, NSW 2170, Australia

R. V. N. Lord $(\bowtie)$

Department of Surgery and Centre for Immunology,

St Vincent's Hospital,

Suite 606, 438 Victoria Street,

Darlinghurst NSW 2010 Sydney, Australia

e-mail: rvlord@stvincents.com.au 
Keywords Barrett's esophagus · Intestinal metaplasia . Esophageal neoplasms $\cdot$ CD83 $\cdot$ Dendritic cells . Inflammation

\section{Introduction}

Barrett's esophagus is the condition in which the normal squamous lining of the distal esophagus is replaced by a metaplastic columnar epithelium containing goblet cells (intestinal metaplasia, IM) in response to chronic severe gastro-esophageal reflux. ${ }^{1-4}$ It is a multistage disease in which IM progresses in a minority of cases to low-grade dysplasia (LGD), high-grade dysplasia (HGD), and eventually esophageal adenocarcinoma. ${ }^{1-4}$ Despite significant improvements in medical and surgical oncology treatments, survival outcomes for patients with this cancer remain poor, with community 5 -year survival rates less than $20 \%{ }^{5}$ For reasons that are not fully known, but probably include an increase in Barrett's esophagus ${ }^{6}$ and a causative association with the increased prevalence of overweight and obesity, ${ }^{7,8}$ there has been a dramatic increase in the incidence of esophageal adenocarcinoma in many Western countries. ${ }^{9,10}$ In the United States, for example, the rate of increase in esophageal adenocarcinoma incidence exceeds that of any other major cancer in the past 25 years, with a more than $600 \%$ increase. $^{9}$

Components of the gastroesophageal refluxate are thought to include the injurious stimuli responsible for the accumulated genetic abnormalities present in Barrett's mucosa. ${ }^{2,3,11}$ It has been reported that premalignant conditions that develop in the presence of chronic inflammation are often associated with the development of an immune response during the progression of the disease. How the immune responses are regulated is poorly understood, ${ }^{12-15}$ but a marked increase has been reported in numbers of T cells and B cells in Barrett's oesophagus. ${ }^{16}$ Antigen-specific T-cell activation is known to critically depend on the interactions of T-cell receptors with antigens presented by specialized antigen-presenting cells ${ }^{17}$ including dendritic cells, a unique family of specialized antigenpresenting cells. ${ }^{18-24}$

Initially described in the skin by Langerhans in 1868 , dendritic cells were identified as antigen-presenting cells in 1973 by the pioneering work of Steinman and Cohn. ${ }^{25}$ Although macrophages, monocytes and $\mathrm{B}$ cells have traditionally been viewed as antigen-presenting cells, dendritic cells, which express high levels of both class I and class II major histocompatibility complex (MHC) molecules and co-stimulatory molecules, are now considered the principal initiators of immune responses by virtue of their unique ability to activate naive $\mathrm{T}$ cells. ${ }^{18-24}$ Dendritic cells arise from a common CD34+ progenitor in the bone marrow and their development involves three stages, for which the terms precursor, immature, and mature, are commonly used. ${ }^{18-24}$ Dendritic cell precursors exit the bone marrow and circulate via the bloodstream to reach their target tissues, taking up residence at sites of potential antigen entry. ${ }^{18-24}$ In this stage, dendritic cells are present in essentially all tissues but are mostly concentrated along epithelial and body cavity surfaces. In these locations, dendritic cells continuously and efficiently sample the antigenic content of their microenvironment by phagocytosis or endocytosis. ${ }^{18-24}$ Antigen is then processed intracellularly, being degraded into short peptides that are loaded onto nascent MHC for subsequent display on the cell surface. Cells with these properties are termed immature or processing dendritic cells as, in this stage, they are yet unable to stimulate T cells. ${ }^{18-24}$ Processing dendritic cells usually exit the nonlymphoid tissues and migrate via the afferent lymph into the lymphoid tissues such as the spleen and lymph nodes, where dendritic cells then complete their maturation. ${ }^{18-24}$ Maturation of dendritic cells involves the down-regulation of endocytotic activity and the upregulation of adhesion molecules and antigen-presenting molecules. Once activated, dendritic cells migrate to the lymphoid tissues where they interact with $\mathrm{T}$ cells and $\mathrm{B}$ cells to initiate and shape the adaptive immune response. ${ }^{18-24}$

The involvement of dendritic cells in tumorigenesis has clinical importance. The infiltration of dendritic cells into some primary tumor types has been found to be associated with significantly improved patient survival and a reduced incidence of recurrent disease, indicating an important immune-regulating role for dendritic cells in the local tumor environment. ${ }^{26-35}$ Furthermore, dendritic cells can be used to manipulate immune responses, including those for cancer immunotherapy.

We undertook this study after a comprehensive literature search failed to find any report of the presence of dendritic cells in Barrett's intestinal metaplasia and esophageal adenocarcinoma.

We now report that dendritic cells are present in Barrett's metaplasia, dysplasia, and adenocarcinoma, and speculate that dendritic cell-dependent lymphocyte activation might occur in this disease.

\section{Material and Methods}

Tissue Specimens and Routine Histology

Endoscopic biopsy or operative surgical specimens were obtained from 37 patients with Barrett's esophagus or esophageal adenocarcinoma. Barrett's esophagus was diagnosed by the presence of a macroscopic area of columnarlined esophagus as well as microscopic intestinal metaplasia 
with goblet cells. Material was collected in accordance with the principles outlined in the Declaration of Helsinki after approved by the Institutional Review Board of St. Vincent's Hospital, Sydney, and informed consent was obtained from each patient. Tissue specimens were processed by standard formalin fixation and paraffin embedding. Paraffin sections cut at 5-7 $\mu \mathrm{m}$ thickness were stained with Mayer's hematoxylin and eosin. After review by an experienced gastrointestinal pathologist, the specimens were classified as Barrett's intestinal metaplasia without dysplasia (IM, $n=12$ ), dysplasia $(n=11)$, and adenocarcinoma $(n=14)$.

\section{Immunohistochemistry and Quantitative Analysis}

Single and double immunostaining for CD83, an inducible glycoprotein belonging to the immunoglobulin superfamily, ${ }^{36}$ was performed. CD83 is important in T-cell immunity mediated by dendritic cells and is the most specific dendritic cell marker. ${ }^{36-40}$ For single immunostaining, after elimination of endogenous peroxidase activity by $3 \% \mathrm{H}_{2} \mathrm{O}_{2}$, sections were preincubated with normal non-immune serum and then tested by avidin-biotin complex using a standard $\mathrm{ABC}$ immunoperoxidase method. ${ }^{41}$ Anti-CD83 (Immunotech; cat no IM-2069) was used in a 1:50 dilution. After washing in
Tris-phosphate buffered saline (TPBS), pH 7.6, the sections were incubated with a biotin-labeled secondary antibody, followed by a treatment with avidin-biotin complex (ELITE ABC, VECTOR PK61000). After washing in TPBS, brown staining was produced by 5-min treatment with 3,3'diaminobenzidine (DAB). All the incubations were completed at room temperature. Archival lymph node sections were used for positive controls. For negative controls, the first antibodies were omitted or the sections were treated with an immunoglobulin fraction of non-immune goat serum as a substitute for the primary antibody. None of the negative control sections showed positive immune staining. Counterstaining was performed with Mayer's hematoxylin.

A computerized quantitative analysis of CD83 expression was carried out at $\times 400$ magnification using the Image-Pro Plus image analysis program (Media Cybernetics, Bethesda, MD.). CD83 expression was measured in each section in at least seven randomly selected microscopic fields containing both CD83+ cells and epithelial glands. Statistical comparison of expression, measured in pixels per standard microscopic field $\left(0.04 \mathrm{~mm}^{2}\right)$, was performed by $t$ test using Prism ${ }^{\circledR} 4$ (GraphPad Software, San Diego, CA.).

Double immunostaining with CD83/CD3 and CD83/CD20 was used to analyze the possible co-localization of dendritic
Figure 1 Typical patterns of distribution of CD83+dendritic cells in biopsy samples of Barrett's metaplasia

(A-G). A Single ABC immunostaining showing the presence of dendritic cells (brown) in the lamina propria surrounding metaplastic glands. B-G Double immunostained sections showing the distribution of $\mathrm{CD} 83+$ dendritic cells and their association with lymphocytes. CD83 antigen was visualized using $\mathrm{ABC}$ immunoperoxidase reaction (brown reaction product) while CD20+ cells $(\mathbf{B}, \mathbf{E}, \mathbf{G})$ and $\mathrm{CD} 3+$ cells $(\mathbf{C}, \mathbf{D}, \mathbf{F})$ were visualized using a Fast red substrate kit (rose reaction product). Counterstaining with Mayer's hematoxylin. In $(\mathbf{E}-\mathbf{G})$, note dendritic cells clustering with lymphocytes. Bars $=100 \mu \mathrm{m}(\mathbf{A}-\mathbf{D})$ and $50 \mu \mathrm{m}(\mathbf{E}-\mathbf{G})$.
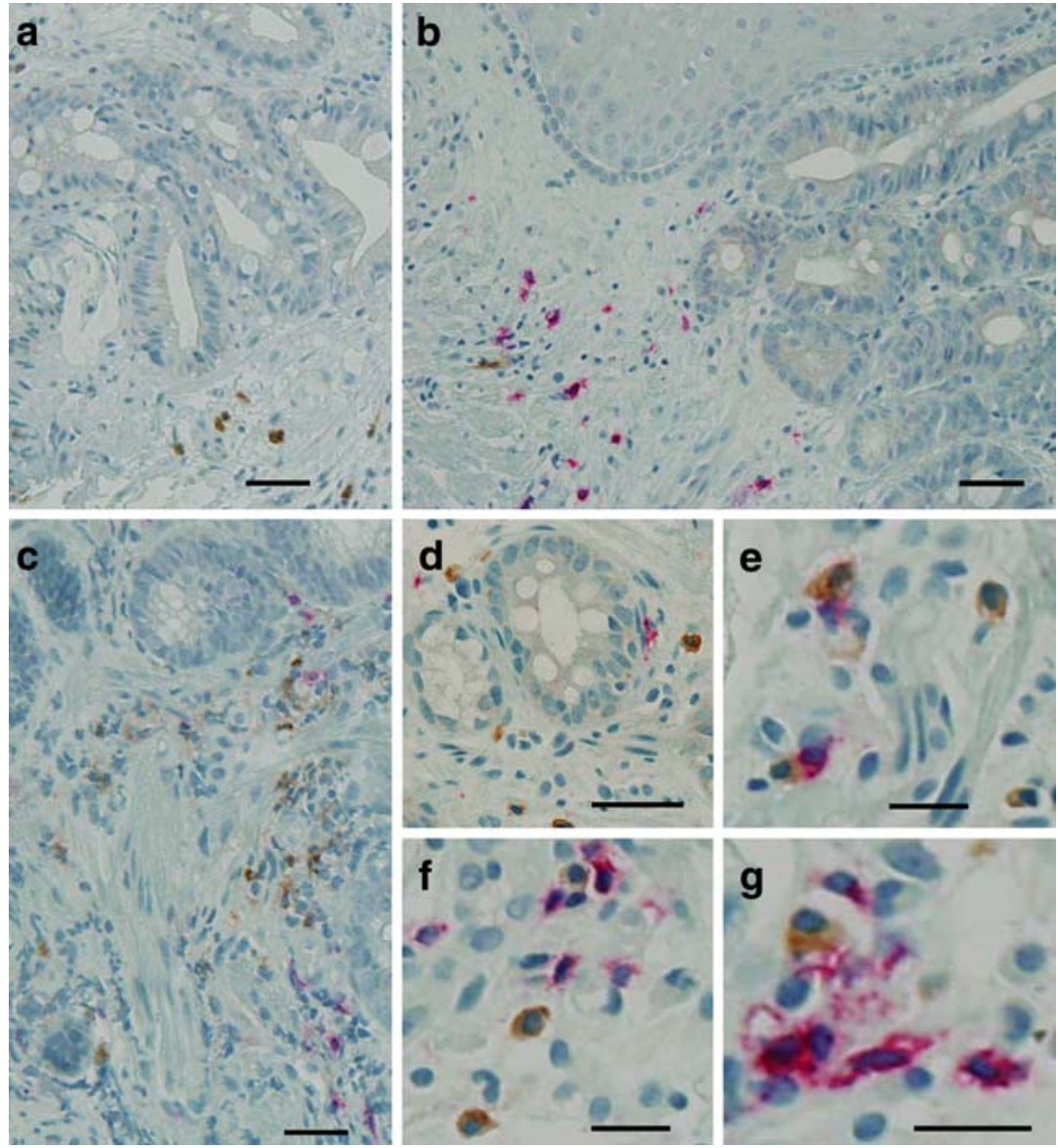
cells with lymphocytes, using previously reported methods. ${ }^{37}$ In brief, after visualization of $\mathrm{CD} 83$ with the $\mathrm{ABC}$ substrate kit, sections were washed with $0.1 \mathrm{M}$ glycine-hydrochloric acid buffer, $\mathrm{pH} 2.2$, and then incubated with anti-CD3 (Dako; cat no A0452; 1:100 dilution) or anti-CD20 antibody (Beckman-Coulter; cat no 1925; 1:50 dilution). After rinsing in TPBS, the sections were incubated with biotinylated secondary antibody and then with alkaline phosphataseconjugated streptavidin (Dako) or with avidin-biotin complex (Dako). A combination of the peroxidaseanti-peroxidase (PAP) and alkaline phosphatase-anti-alkaline phosphatase (APAAP) techniques, with antigen visualization with DAB or Fast Red, was also used. Controls were as for single immunostaining.

\section{Electron Microscopy}

Fresh endoscopic biopsy specimens were fixed in 2.5\% glutaraldehyde in $0.1 \mathrm{M}$ sodium cacodylate buffer ( $\mathrm{pH} 7.4$ ), routinely processed and embedded in Spurr resin. Ultrathin sections were stained with uranyl acetate and lead citrate and examined with the aid of a Morgagni 268D electron microscope. The electron microscopic identification of dendritic cells was carried out according to their distinctive ultrastructural features, which include the tubulovesicular system and atypical granules as previously used. ${ }^{19,} 42$

\section{Results}

CD83 expression was identified in all 12 specimens with Barrett's IM without dysplasia. The numbers of CD83+ dendritic cells varied markedly in different specimens and the cells were irregularly distributed throughout the lamina propria (Fig. 1A). The intensity of CD83 immunopositivity in individual cells varied notably as well, but in all specimens, dendritic cells located in close proximity to intestinal glands showed a lower intensity of immunopositivity than those located at a distance in areas of the lamina propria enriched by capillary networks. Double immunostaining utilizing combinations of anti-CD83, anti-CD20, and anti-CD3 antibodies revealed that all specimens contained various numbers of $\mathrm{B}$ cells $(\mathrm{CD} 20+)$ and $\mathrm{T}$ cells $(\mathrm{CD} 3+)$ and that dendritic cells, T- cells, and B-cells frequently formed clusters within the lamina propria (Fig. 1B-G).

CD83+ cells were present between dysplastic glands in all Barrett's dysplasia tissue specimens, often with a patchy distribution in the lamina propria (Fig. 2A,B) due to frequent clustering of dendritic cells (Fig. 2C). Direct contacts between dendritic cells and lymphocytes, including $\mathrm{T}$ and $\mathrm{B}$ cells, were also identified (Fig. 2C-E). When $\mathrm{CD} 83+$ dendritic cells were detected within inflammatory cell infiltrates in the lamina propria, each individual
Figure 2 CD83+ dendritic cells in biopsy samples containing dysplastic changes in specialized intestinal type mucosa of Barrett's esophagus (A-F). CD83 antigen was visualized using $\mathrm{ABC}$ immunoperoxidase reaction (brown reaction product) while $\mathrm{CD} 20+$ cells $(\mathbf{A}, \mathbf{E}, \mathbf{F})$ and $\mathrm{CD} 3+$ cells $(\mathbf{B}, \mathbf{C}, \mathbf{D})$ were visualized using a Fast red substrate kit (rose reaction product). Counterstaining with Mayer's hematoxylin. In $(\mathbf{C})$, note dendritic cells clustering with each other while in $(\mathbf{D}, \mathbf{E})$, close apposition between dendritic cells and lymphocytes is evident. F Association of dendritic cells with lymphocytes within an immuneinflammatory infiltrate in the lamina propria. Bars $=100 \mu \mathrm{m}$ $(\mathbf{A}, \mathbf{B})$ and $50 \mu \mathrm{m}(\mathbf{C}, \mathbf{F})$ and $25 \mu \mathrm{m}(\mathbf{D}, \mathbf{E})$.

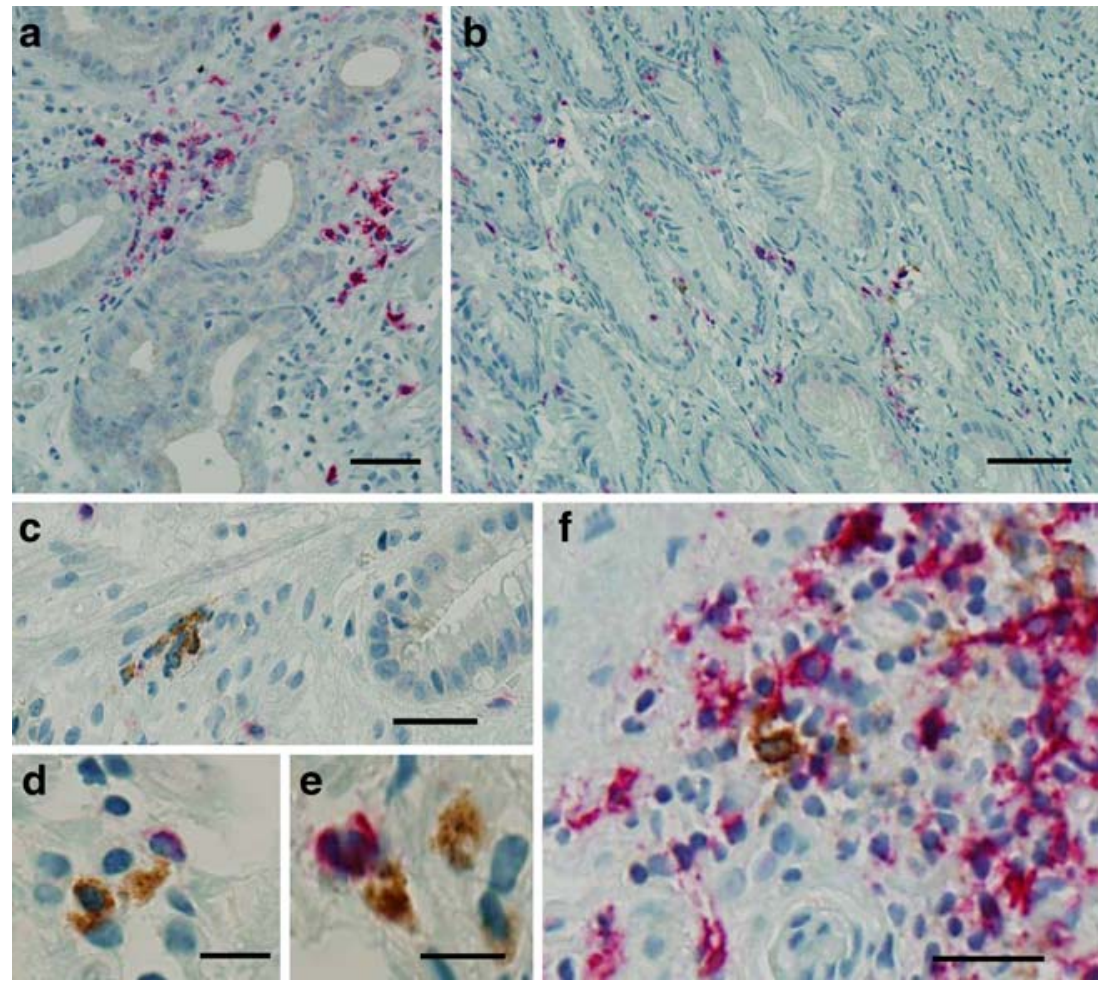


dendritic cell seemed to cluster with several lymphocytes (Fig. 2F).

CD83+ dendritic cells were detected in all esophageal adenocarcinoma specimens. Similar to the pattern seen in the Barrett's dysplasia tissues, dendritic cells were distributed mosaically in clusters between distorted glands (Fig. 3A-E). Double immunostaining demonstrated direct contacts between dendritic cells and $\mathrm{T}$ and $\mathrm{B}$ cells in all specimens studied. Notably, contacts between CD83+ dendritic cells and lymphocytes were regularly seen in close proximity to capillaries (Fig. 3F) and dendritic cells were frequently observed within the lumen of capillaries forming networks within the lamina propria (Fig. 3G).

There was no significant difference between the mean CD83 expression in specimens of Barrett's IM (599 \pm 145$)$ compared to Barrett's dysplasia tissues $(730 \pm 167)$ on the computerized analysis (Fig. 4A). However, CD83 expression was significantly higher in adenocarcinoma specimens (1235 \pm 139$)$ compared to either IM or dysplasia tissues (Fig. 4A). Figure 4 also shows the significantly higher CD83 expression in adenocarcinoma compared to nonadenocarcinoma Barrett's tissues ( $1235 \pm 139$ vs $662+109$; $p=0.0026$, all Student's $t$ test).

The presence of dendritic cells was investigated further using electron microscopy. Cells with the typical appearance of dendritic cells in other tissues ${ }^{19,42}$ were readily identified. The direct contacts between esophageal dendritic cells and lymphocyte-like cells as well as between dendritic cells and plasma cells were also detected (Figs. 5A-F, 6A-C. and 7A-D). Similar to dendritic cells elsewhere, dendritic cells in the esophagus were characterized by a cytoplasm of low electron density, which contained a tubulovesicular system
Figure 3 Patterns of distribution of $\mathrm{CD} 83+$ dendritic cells and their association with lymphocytes in esophageal adenocarcinoma tissue specimens (A-G). CD83 antigen was visualized using $\mathrm{ABC}$ immunoperoxidase reaction (brown reaction product) while CD3 + cells $(\mathbf{A}-\mathbf{D}, \mathbf{F})$ and CD20 + cells (E) were visualized using a Fast red substrate kit (rose reaction product). Counterstaining with Mayer's hematoxylin. (C) is a detail of (A). In (F), note a contact of a dendritic cell with a lymphocyte in close proximity to a capillary. G Low magnification image showing the presence of dendritic cells within lumens of capillaries forming a network in an adenocarcinoma tissue specimen; dendritic cells are also seen around capillaries in the lamina propria. Bars $=150 \mu \mathrm{m}$ $(\mathbf{A}, \mathbf{G})$ and $100 \mu \mathrm{m}(\mathbf{B}), 50 \mu \mathrm{m}$ (D, F) $25 \mu \mathrm{m}(\mathbf{E})$.
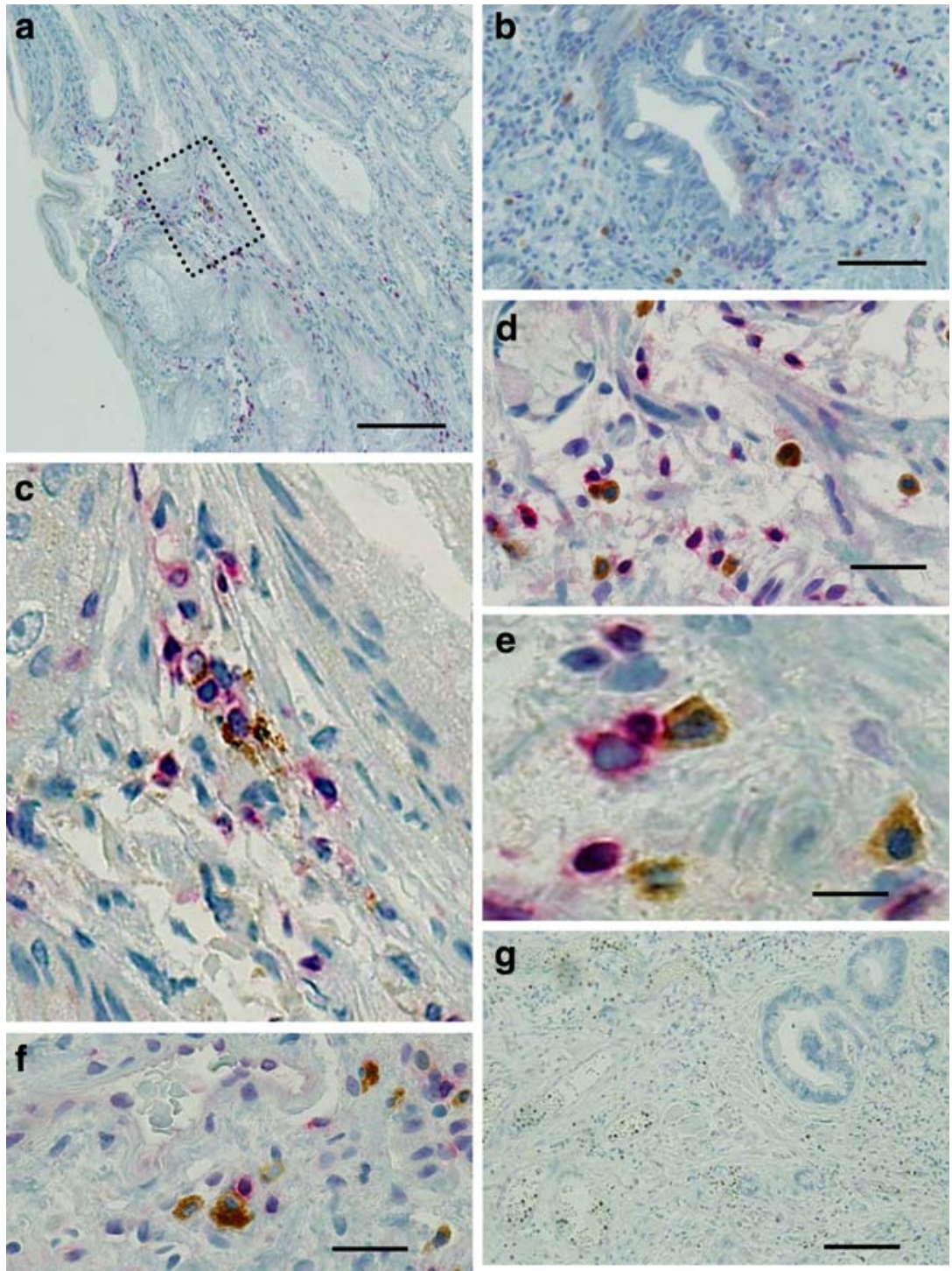
unique to cells of the dendritic cell family (Figs. 5D, 6A-C, $7 \mathrm{~B}, \mathrm{D})$. Atypical granules were present in some esophageal dendritic cells (Figs. 6A,B and 7A,B), but their cytoplasm lacked liposomes, rest bodies, or other organelles excluding the Golgi complex (Figs. 5A-F, 6A-C, and 7A-D). As with other dendritic cells, esophageal dendritic cells possessed long cell processes, the continuity of which with the dendritic cell body could be established in serial ultrathin sections (Figs. 6B and 7B). The cytoplasmic content of dendritic cell processes was limited either by granular and agranular material of medium and low electron density, respectively (Fig. 1B,E), or cisterns of the tubulovesicular system had developed in the cell processes (Figs. 6A,B and 7B). Through multiple cell processes, dendritic cells contacted $\mathrm{T}$ cell like cells (Fig. 1A-D) and plasma cells (Fig. 5E-F) or, alternatively, close apposition of the cell
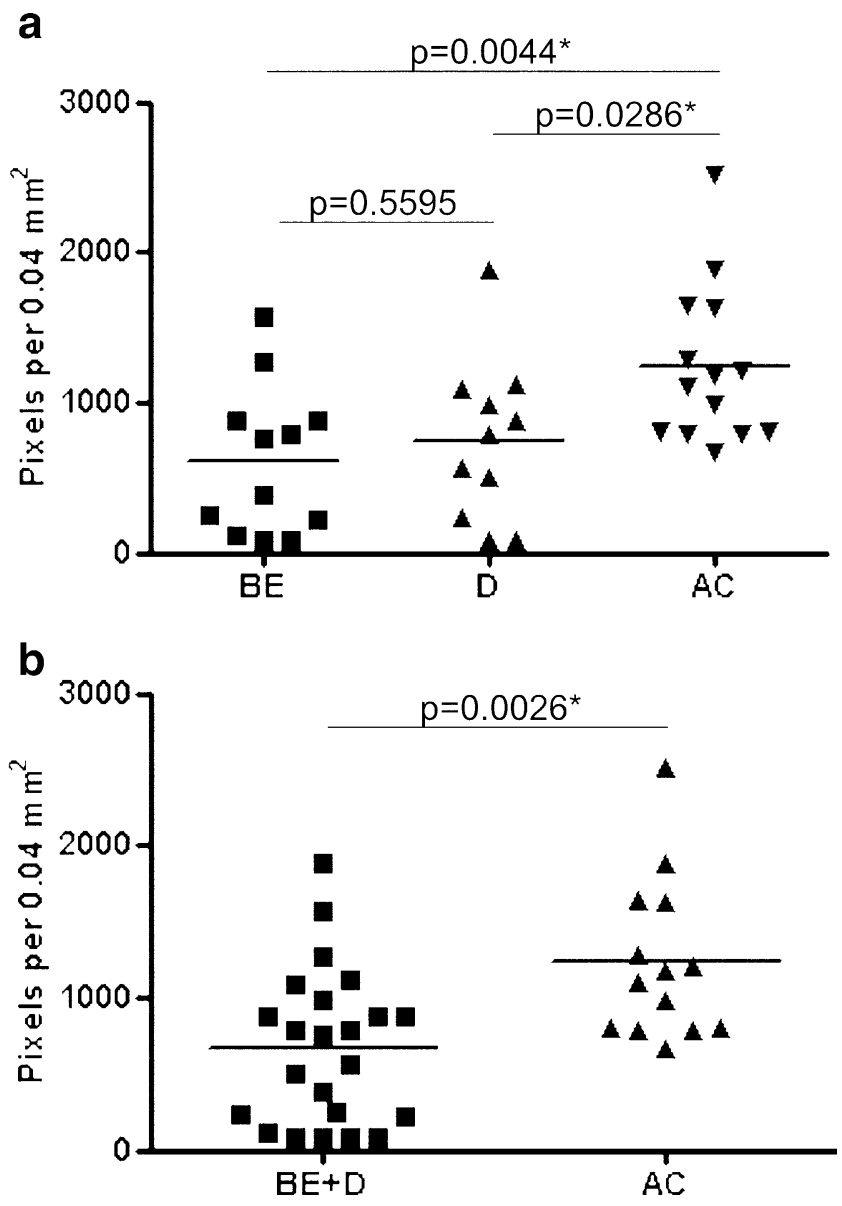

Figure 4 Expression of CD83 antigen in specialized intestinal type mucosa of Barrett's esophagus without dysplasia $(B E)$, dysplasia $(D)$ and adenocarcinoma $(A C)$ evaluated as a number of pixel per standard field using a computerized quantitative analysis (A) (see "Material and methods" section). In (B), the expression of CD83 antigen in specimens without adenocarcinoma $(B E+D)$ compared with that in adenocarcinoma specimens $(A C)$. bodies of dendritic cells and lymphocytes was observed (Figs. 6A and 7A).

Histologically normal stratified squamous epithelium was present in some sections. There were only very rare CD83+ dendritic cells, and no glands, in the lamina propria underlying the normal squamous esophagus areas. Dendritic cells had a similar appearance in normal esophagus and Barrett's diseases.

\section{Discussion}

This study demonstrates, by both immunohistochemistry and electron microscopy, that dendritic cells reside in Barrett's esophagus and esophageal adenocarcinoma. The certainty of this finding is supported by the studies ${ }^{36-40}$ reporting that $\mathrm{CD} 83$ is a specific marker for the identification of dendritic cells, by the typical dendritic cell appearance of the CD83+ cells found in Barrett's tissues, and, importantly, by the demonstration of the presence of cells with structural features unique to the dendritic cell family (tubulovesicular system and atypical granules) by electron microscopy.

The unambiguous identification of dendritic cells is essential because, to our knowledge, this is the first report of the presence of dendritic cells in Barrett's esophagus and esophageal adenocarcinoma. The novelty of this report is somewhat surprising in view of the interest in dendritic cell immunotherapy for cancers, including esophageal adenocarcinoma, ${ }^{43}$ and indicates that there is a pressing need for further studies investigating the regulation of the immune response in this disease.

According to the concept of immune surveillance, the immune system is able to recognize and destroy a clone of transformed cells before the clone becomes cancer. ${ }^{44}$ However, evidence from experimental and clinical observations shows that the immune system does not behave in this way for many tumor types. ${ }^{44}$ Most tumor antigens are weakly immunogenic and the immune functions, such as the antigen-specific T-cell response initiated by professional antigen-presenting cells, and immune regulation mediated by regulatory cells often fail to operate adequately and thus fail to prevent tumor growth. ${ }^{44-46}$ The importance of dendritic cells in immune surveillance suggests that infiltration of dendritic cells into tumors should have prognostic significance, ${ }^{44-46}$ but this has not been a consistent finding. An increased infiltration of dendritic cells into esophageal squamous cell carcinoma and hepatocellular carcinoma is associated with good prognosis for patients with such cancers, ${ }^{47-49}$ but there was no significant association with prognosis in two studies of patients with renal cell carcinoma, for example. ${ }^{50-52}$ As an explanation for these variable findings, Mailliard et al. ${ }^{53}$ suggest that 
Figure 5 Electron micrographs showing close apposition between dendritic cells and $\mathrm{T}$ cells $(\mathbf{A}-\mathbf{D})$ as well as between a dendritic cell process and a plasma cell $(\mathbf{E}-\mathbf{F})$. (B) is a detail of $(\mathbf{A})$; (D) is a detail of $(\mathbf{C})$; $(\mathbf{F})$ is a detail of $(\mathbf{E})$. In $(\mathbf{B}, \mathbf{D}$, and $\mathbf{F}$ ), dendritic cells are marked by stars. Bars $=15 \mu \mathrm{m}$ (A), $4 \mu \mathrm{m}(\mathbf{C})$, and $20 \mu \mathrm{m}(E)$.
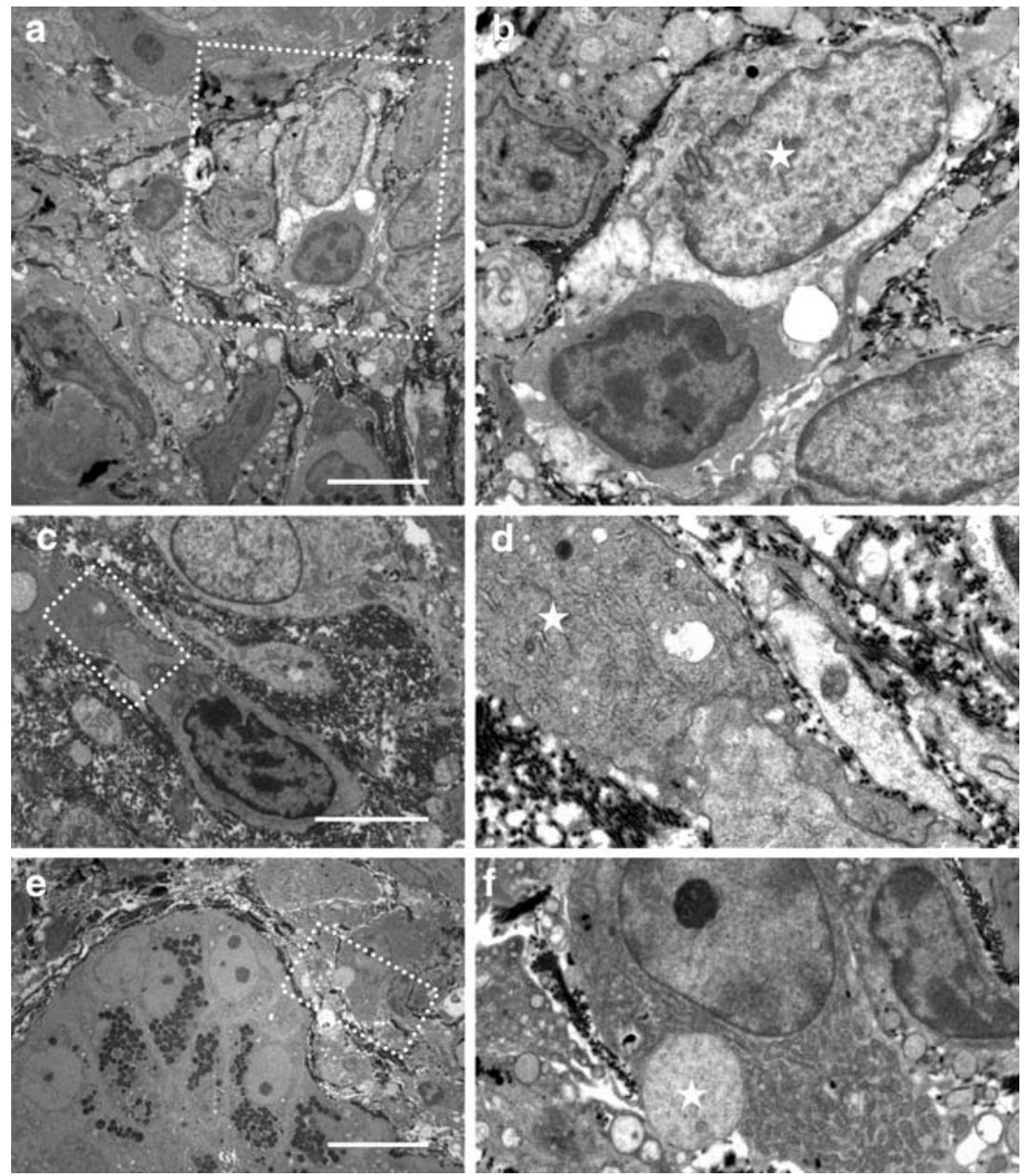

infiltrating dendritic cells might promote T-cell survival or death, depending on their maturation stage and function.

We found significantly increased numbers of dendritic cells in adenocarcinoma compared to benign Barrett's tissues. Indeed, the density of dendritic cells in the cancer sections studied is among the highest, and perhaps the highest reported for any non-cultured tissue. ${ }^{19}$ This descriptive study does not address whether dendritic cells may have a mechanistic role in the development and progression of Barrett's disease, but an involvement in local processes associated with the development of adenocarcinoma in the columnar epithelium is at least suggested. One mechanism for dendritic cell involvement is that, although the numbers of dendritic cells are increased, those residing in cancer tissues can be defective. Such a possibility is in agreement with the view that the defect of dendritic cells is one of the important factors leading to the immune escape of tumor growth. ${ }^{54,55} \mathrm{~A}$ consequence of the maturation of defective dendritic cells can be a decrease in functionally competent dendritic cells. ${ }^{54,55}$ Increased numbers of functionally incompetent dendritic cells can induce the tolerance of $\mathrm{T}$ cells, resulting in the tumor escaping from the surveillance of the immune system. ${ }^{54,55}$ In renal cell carcinoma and prostate cancer, infiltrated dendritic cells have lower allostimulatory activity, while dendritic cells in the peripheral blood of patients with breast cancer express lower levels of both MHC II and co-stimulatory molecules. ${ }^{54,55}$ Almand et al. ${ }^{55}$ reported that despite that the increase in the numbers of dendritic cells in lymph nodes and peripheral blood, their ability to induce antigen-specific proliferation of autologous $\mathrm{T}$ cells is significantly decreased.

The present immunohistochemical analysis revealed that dendritic cells frequently contact both $\mathrm{T}$ cells and $\mathrm{B}$ cells in Barrett's esophagus and adenocarcinoma, and the electron microscopic analysis showed that dendritic cells form direct contacts with $\mathrm{T}$ cells through their long cellular processes. As found in other tissues, ${ }^{19,42,56}$ the tubulovesicular system in the dendritic cell processes that contact $\mathrm{T}$ cells is highly hypertrophied, indicating dendritic cell activation. Although not the focus of this study, similar to the report by Moons et al., ${ }^{16}$ we found a large number of plasma cells in Barrett's esophagus, indicating that a significant humoral 

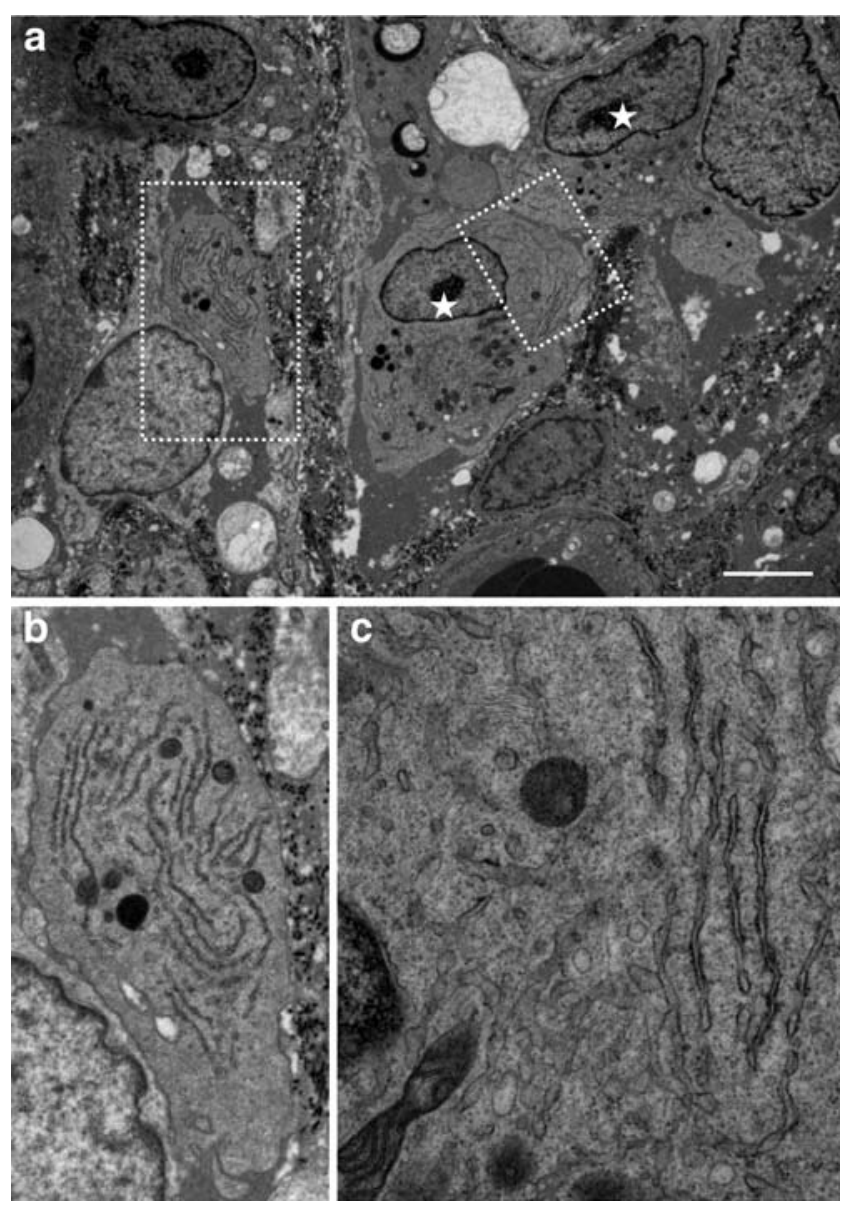

Figure 6 A group of dendritic cells (A) exhibiting highly hypertrophied tubulovesicular system in their cellular processes $(\mathbf{A}, \mathbf{B})$ and in the perinuclear cytoplasm $(\mathbf{A}, \mathbf{C})$. In $(\mathbf{A})$, dendritic cells are marked by stars. An esophageal adenocarcinoma specimen. Bar $=6 \mu \mathrm{m}$.

immune response is occurring locally within the lamina propria. Plasma cells with highly developed rough endoplasmic reticulum were seen in direct contact with dendritic cells, suggesting a role for dendritic cells in the regulation of immune reactions in esophageal pathology. Dendritic cells were found around and within capillaries in the lamina propria, further suggesting that esophageal dendritic cells might also migrate in the immune organs by means of the classical dendritic cell pathway. ${ }^{18-24}$

The identification of dendritic cells in Barrett's esophagus and esophageal adenocarcinoma has potential clinical importance. The remarkable ability of dendritic cells to elicit or diminish immune responses and the availability of sophisticated dendritic cell culture systems have stimulated the use of dendritic cells in cancer immunotherapy. ${ }^{18-24,57}$ Recent achievements in loading dendritic cells with appropriate antigens have made it possible to produce in vitro dendritic cells with desirable properties ${ }^{57}$ Remarkable progress in the field of cellular vaccination has been achieved by means of genetic engineering of tolerogenic dendritic cells. ${ }^{57}$ The very high density of dendritic cells in esophageal adenocarcinoma in this study supports efforts to develop dendritic cell immunotherapy for this cancer. The findings also suggest further studies on the prognostic significance of dendritic cell infiltration for progression to more advanced Barrett's stages and for the prognosis of patients with Barrett's cancer.

The scope of the present work was to investigate and report the presence of dendritic cells in Barrett's esophagus and esophageal adenocarcinoma and the observation that the number of dendritic cells in the cancers was significantly higher than in non-malignant Barrett's. Further studies are required in order to examine the prognostic value and functional characteristics of dendritic cells in this disease.
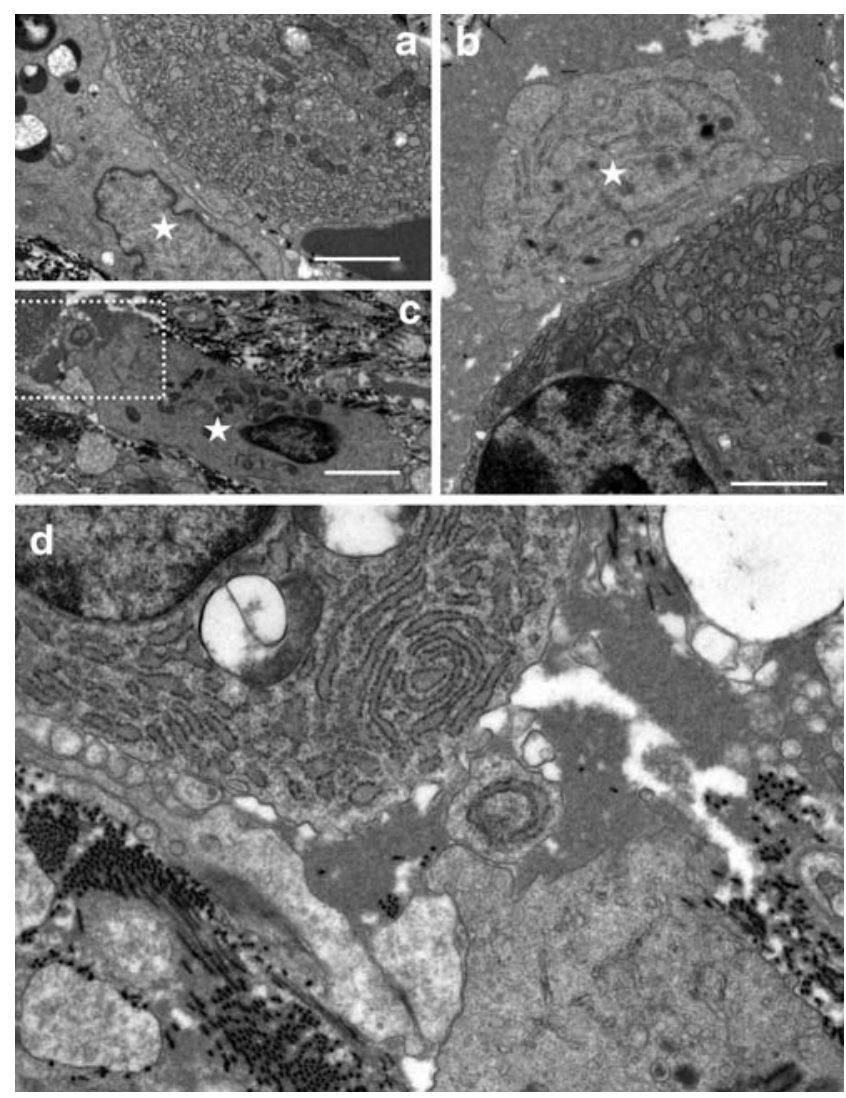

Figure 7 Direct contacts between dendritic cells and plasma cells (AD). In (A-C), dendritic cells are marked by stars. Image (A) shows a close apposition of dendritic cell body to the plasma cell plasmalemma along a distance exceeding $3 \mu \mathrm{m}$ while image (B) shows a contact of a dendritic cell process with the plasma cell body. In (B), note the presence of well-developed cisterns of the tubulovesicular system in a dendritic cell process while in (A), note the presence of atypical granules in the cytoplasm of the dendritic cell. C, D A direct contact between a dendritic cell microvillus and a short process of a plasma cell. (D) is a detail of (C). Bars $=3 \mu \mathrm{m}(\mathbf{A}, \mathbf{C})$ and $2 \mu \mathrm{m}(\mathbf{B})$. 
Acknowledgments We thank the National Health and Medical Research Council, Cancer Institute NSW, and St. Vincent's Clinic Foundation, Sydney, for financial support.

Open Access This article is distributed under the terms of the Creative Commons Attribution Noncommercial License which permits any noncommercial use, distribution, and reproduction in any medium, provided the original author(s) and source are credited.

\section{References}

1. Lagergren J, Bergstrom R, Lindgren A, Nyren O. Symptomatic gastroesophageal reflux as a risk factor for esophageal adenocarcinoma. N Engl J Med 1999;340:825-831. doi:10.1056/ NEJM199903183401101.

2. Lord RV. Genetic basis of the Barrett's metaplasia, dysplasia, adenocarcinoma sequence. Probl Gen Surg 2001;18:53-70. doi:10.1097/00013452-200106000-00008.

3. Kerkhof M, Kusters JG, van Dekken H, Kuipers EJ, Siersema PD. Biomarkers for risk stratification of neoplastic progression in Barrett esophagus. Cell Oncol 2007;29:507-517.

4. Quinlan JM, Colleypriest BJ, Farrant M, Tosh D. Epithelial metaplasia and the development of cancer. Biochim Biophys Acta 2007;1776:10-21.

5. Jemal A, Siegel R, Ward E, Murray T, Xu J, Thun MJ. Cancer statistics, 2007. CA Cancer J Clin 2007;57:43-66.

6. Kendall BJ, Whiteman DC. Temporal changes in the endoscopic frequency of new cases of Barrett's esophagus in an Australian health region. Am J Gastroenterol 2006;101:1178-1182. doi:10.1111/j.1572-0241.2006.00548.x.

7. Lagergren J, Bergstrom R, Nyren O. Association between body mass and adenocarcinoma of the esophagus and gastric cardia. Ann Intern Med 1999;130:883-890.

8. Whiteman DC, Sadeghi S, Pandeya N et al. Combined effects of obesity, acid reflux and smoking on the risk of adenocarcinomas of the oesophagus. Gut 2008;57:173-180. doi:10.1136/ gut.2007.131375.

9. Pohl H, Welch HG. The role of overdiagnosis and reclassification in the marked increase of esophageal adenocarcinoma incidence. $\mathrm{J}$ Natl Cancer Inst 2005;97:142-146.

10. Lord RV, Law MG, Ward RL, Giles GG, Thomas RJ, Thursfield V. Rising incidence of oesophageal adenocarcinoma in men in Australia. J0 Gastroenterol Hepatol 1998;13:356-362. doi:10.1111/j.1440-1746.1998.tb00646.x.

11. Solaymani-Dodaran M, Logan RF, West J, Card T, Coupland C. Risk of oesophageal cancer in Barrett's oesophagus and gastrooesophageal reflux. Gut 2004;53:1070-1074. doi:10.1136/ gut.2003.028076.

12. O'Byrne KJ, Dalgleish AG. Chronic immune activation and inflammation as the cause of malignancy. $\mathrm{Br} \mathrm{J}$ Cancer 2001;85:473-483. doi:10.1054/bjoc.2001.1943.

13. Dalgleish AG, O'Byrne KJ. Chronic immune activation and inflammation in the pathogenesis of AIDS and cancer. Adv Cancer Res 2002;84:231-276. doi:10.1016/S0065-230X(02)84008-8.

14. Macarthur M, Hold GL, El-Omar EM. Inflammation and cancer II $\$$ role of chronic inflammation and cytokine gene polymorphisms in the pathogenesis of gastrointestinal malignancy. Am J Physiol Gastrointest Liver Physiol 2004;286:G515-G520. doi:10.1152/ ajpgi.00475.2003.

15. Hadden JW. Immunodeficiency and cancer: prospects for correction. Int Immunopharmacol 2003;3:1061-1071. doi:10.1016/S1567-5769 (03)00060-2.
16. Moons LM, Kusters JG, Bultman E et al. Barrett's oesophagus is characterized by a predominantly humoral inflammatory response. J Pathol 2005;207:269-276. doi:10.1002/path.1847.

17. Cronin SJ, Penninger JM. From T-cell activation signals to signaling control of anti-cancer immunity. Immunol Rev 2007;220:151-168. doi:10.1111/j.1600-065X.2007.00570.x.

18. Banchereau J, Steinman RM. Dendritic cells and control of immunity. Nature 1998;392:245-252. doi:10.1038/32588.

19. Lotze MT, Thomson AW. Dendritic Cells: Biology and Clinical Applications. 2nd ed. San Diego, CA: Academic, 2001.

20. Lipscomb MF, Masten BJ. Dendritic cells: immune regulators in health and disease. Physiol Rev 2002;82:97-130.

21. Steinman RM, Hawiger D, Nussenzweig MC. Tolerogenic dendritic cells. Annu Rev Immunol 2003;21:685-711. doi:10.1146/annurev.immunol.21.120601.141040.

22. Heath WR, Belz GT, Behrens GM et al. Cross-presentation, dendritic cell subsets, and the generation of immunity to cellular antigens. Immunol Rev 2004;199:9-26. doi:10.1111/j.01052896.2004.00142.x.

23. de Jong EC, Smits HH, Kapsenberg ML. Dendritic cell-mediated $\mathrm{T}$ cell polarization. Springer Semin Immunopathol 2005;26:289307. doi:10.1007/s00281-004-0167-1.

24. Steinman RM, Banchereau J. Taking dendritic cells into medicine. Nature 2007;449:419-426. doi:10.1038/nature06175.

25. Steinman RM, Cohn ZA. Identification of a novel cell type in peripheral lymphoid organs of mice: I. Morphology, quantification, tissue distribution. J Exp Med 1973;137:1142-1162. doi:10.1084/jem.137.5.1142.

26. Dadabayev AR, Sandel MH, Menon AG et al. Dendritic cells in colorectal cancer correlate with other tumor-infiltrating immune cells. Cancer Immunol Immunother 2004;53:978-986. doi:10.1007/s00262-004-0548-2.

27. Alavaikko MJ, Blanco G, Aine R et al. Follicular dendritic cells have prognostic relevance in Hodgkins disease. Am J Clin Pathol 1994;101:761-767.

28. Ambe K, Mori M, Enjoji M. S-100 protein-positive dendritic cells in colorectal adenocarcinomas: distribution and relation to the clinical prognosis. Cancer 1989;63:496-503. doi:10.1002/ 1097-0142(19890201)63:3<496::AID-CNCR2820630318>3.0. $\mathrm{CO} ; 2-\mathrm{K}$.

29. Bethwaite PB, Holloway LJ, Thornton A, Delahunt B. Infiltration by immunocompetent cells in early stage invasive carcinoma of the uterine cervix: a prognostic study. Pathology 1996;28:321327. doi:10.1080/00313029600169274.

30. Furihata M, Ohtsuki Y, Ido E et al. HLA-DR antigen- and S-100 protein-positive dendritic cells in esophageal squamous cell carcinoma - their distribution in relation to prognosis. Virchows Arch B Cell Pathol Incl Mol Pathol 1992;61:409-414. doi:10.1007/BF02890444.

31. Giannini A, Bianchi S, Messerini L et al. Prognostic significance of accessory cells and lymphocytes in nasopharyngeal carcinoma. Pathol Res Pract 1991;187:496-502.

32. Inoue K, Furihata M, Ohtsuki Y, Fujita Y. Distribution of S-100 protein-positive dendritic cells and expression of HLA-DR antigen in transitional cell carcinoma of the urinary bladder in relation to tumour progression and prognosis. Virchows Arch A Pathol Anat Histopathol 1993;422:351-355. doi:10.1007/BF01605452.

33. Ishigami $\mathrm{S}$, Natsugoe $\mathrm{S}$, Tokuda $\mathrm{K}$ et al. Clinical impact of intratumoral natural killer cell and dendritic cell infiltration in gastric cancer. Cancer Lett 2000;159:103-108. doi:10.1016/ S0304-3835(00)00542-5.

34. Mori M, Ambe K, Adachi $Y$ et al. Prognostic value of immunohistochemically identified CEA, SC, AFP, and S-100 protein-positive cells in gastric carcinoma. Cancer 1988;62:534 540. doi:10.1002/1097-0142(19880801)62:3<534::AIDCNCR2820620316>3.0.CO;2-\#. 
35. Reichert TE, Scheuer C, Day R, Wagner W, Whiteside TL. The number of intratumoral dendritic cells and zeta-chain expression in $\mathrm{T}$ cells as prognostic and survival biomarkers in patients with oral carcinoma. Cancer 2001;91:2136-2147. doi:10.1002/10970142(20010601)91:11<2136::AID-CNCR1242>3.0.CO;2-Q.

36. Berchtold S, Mühl-Zürbes P, Maczek E, Golka A, Schuler G, Steinkasserer A. Cloning and characterization of the promoter region of the human CD83 gene. Immunobiology 2002;205:231246. doi:10.1078/0171-2985-00128.

37. Lechmann M, Zinser E, Golka A, Steinkasserer A. Role of CD83 in the immunomodulation of dendritic cells. Int Arch Allergy Immunol 2002;129:113-118. doi:10.1159/000065883.

38. Breloer M, Kretschmer B, Lüthje K et al. CD83 is a regulator of murine B cell function in vivo. Eur J Immunol 2007;37:634-648. doi:10.1002/eji.200636852.

39. Fujimoto $\mathrm{Y}, \mathrm{Tu} \mathrm{L}$, Miller AS et al. CD83 expression influences CD4+ T cell development in the thymus. Cell 2002;108:755-767. doi:10.1016/S0092-8674(02)00673-6.

40. Lechmann M, Krooshoop DJ, Dudziak D et al. The extracellular domain of CD83 inhibits dendritic cell-mediated T cell stimulation and binds to a ligand on dendritic cells. J Exp Med 2001;194:1813-1821. doi:10.1084/jem.194.12.1813.

41. Bobryshev YV, Lord RS. Mapping of vascular dendritic cells in atherosclerotic arteries suggests their involvement in local immune-inflammatory reactions. Cardiovasc Res 1998;37:799_ 810. doi:10.1016/S0008-6363(97)00229-0.

42. Bobryshev YV, Lord RSA. Ultrastructural recognition of cells with dendritic cell morphology in human aortic intima. Contacting interactions of vascular dendritic cells in athero-resistant and athero-prone areas of the normal aorta. Arch Histol Cytol 1995;58:307-322. doi:10.1679/aohc.58.307.

43. Milano F, Rygiel AM, Buttar $\mathrm{N}$ et al. An ex vivo readout for evaluation of dendritic cell-induced autologous cytotoxic $\mathrm{T}$ lymphocyte responses against esophageal cancer. Cancer Immunol Immunother 2007;56:1967-1977. doi:10.1007/s00262-0070341-0.

44. Abbas AK, Lichtman AH. Immunity to tumor. In Abbas AK, Lichtman AH, eds. Cellular and molecular immunology, 5th ed. USA: Saunders, 2003, pp 391-410.

45. Greten TF, Jaffee EM. Cancer vaccines. J Clin Oncol 1999;17:1047-1060.
46. Gabrilovich D. Mechanisms and functional significance of tumorinduced dendritic-cell defects. Nat Rev Immunol 2004;4:941-952. doi:10.1038/nri1498.

47. Byrne S, Halliday GM. Dendritic cells: making progress with tumour regression? Immunol Cell Biol 2002;80:520-530. doi:10.1046/j.1440-1711.2002.01122.x.

48. Furihata M, Ohtsuki $\mathrm{Y}$, Sonobe $\mathrm{H}$ et al. Prognostic significance of simultaneous infiltration of HLA-DRpositive dendritic cells and tumor infiltrating lymphocytes into human esophageal carcinoma. Tohoku J Exp Med 1993;169:187-195. doi: 10.1620/tjem.169.187.

49. Yang W, Yu J. Immunologic function of dendritic cells in esophageal cancer. Dig Dis Sci 2008;53:1739-1746. Review. doi:10.1007/s10620-007-0095-8.

50. Ido E, Furihata M, Ohtsuki Y, Iwata J, Sonobe H. S-100 protein positive dendritic cells detected in hepatocellular carcinoma in relation to tumor progression and prognosis. Int J Oncol 1994;5:231-236.

51. Thurnher M, Radmayr C, Ramoner R et al. Human renal-cell carcinoma tissue contains dendritic cells. Int J Cancer 1996;68:1-7. doi:10.1002/ (SICI)1097-0215(19960927)68:1<1::AID-IJC1>3.0.CO;2-V.

52. Troy AJ, Summers KL, Davidson PJ, Atkinson CH, Hart DN. Minimal recruitment and activation of dendritic cells within renal cell carcinoma. Clin Cancer Res 1998;4:585-593.

53. Mailliard RB, Dallal RM, Son YI, Lotze MT. Dendritic cells promote T-cell survival or death depending upon their maturation state and presentation of antigen. Immunol Invest 2000;29:177185. doi:10.3109/08820130009062302.

54. Gabrilovich DI, Corak J, Ciernik IF, Kavanaugh D, Carbone DP. Decreased antigen presentation by dendritic cells in patients with breast cancer. Clin Cancer Res 1997;3:483-490.

55. Almand B, Resser JR, Lindman B et al. Clinical significance of defective dendritic cell differentiation in cancer. Clin Cancer Res 2000;6:1755-1766.

56. Takahashi K, Naito M, Shultz LD, Hayashi S, Nishikawa S. Differentiation of dendritic cell populations in macrophage colony-stimulating factor-deficient mice homozygous for the osteopetrosis (op) mutation. J Leukoc Biol 1993;53:19-28.

57. Markiewicz MA, Kast WM. Progress in the development of immunotherapy of cancer using ex vivo-generated dendritic cells expressing multiple tumor antigen epitopes. Cancer Invest 2004;22:417-434. doi:10.1081/CNV-200029072. 